\title{
SENDAS DE MACAU: CAMILO PESSANHA E A PAISAGEM DO ORIENTE
}

\author{
Fernando Ulisses Mendonça Serafim ${ }^{1}$
}

RESUMO: As "paisagens" orientais que Camilo Pessanha testemunhou e comunicou, por meio de crônicas e ensaios, ostentam juízos de valor muito particulares, expressos nos seus comentários sobre os cenários de Macau e de províncias chinesas próximas. Se, por um lado, as imagens do Oriente não são um de seus temas mais frequentes em sua poesia, por outro a sua prosa ensaística se nutre de variadas fontes e referências da sinologia. Este trabalho pretende analisar as relações entre alguns ensaios de Camilo Pessanha e os ideais subjacentes à observação das cidades orientais, comparando-a a outros relatos semelhantes de sinólogos de seu tempo, a fim de elucidar certas interpretações conferidas a determinados aspectos da cultura chinesa.

PALAVRAS-CHAVE: sinologia; Macau; orientalismo.

\section{PATHS OF MACAU: CAMILO PESSANHA AND THE ORIENTAL LANDASCAPE}

\begin{abstract}
The Eastern "landscapes" that Camilo Pessanha witnessed and communicated, through chronicles and essays, support very particular value judgments, expressed by his comments about settings from Macau and nearby Chinese provinces. Whether, on the one hand, the Eastern images are not one of the most frequent subjects in his poetry, on the other hand, his essayistic prose is inspired by many sources and references of sinology. This paper aims to analyze the relationship between some Camilo Pessanha's essays and the ideals which underly the observation of the oriental cities, comparing them to other similar reports provided by sinologists of Pessanha's time, in order to understand certain interpretations attributed to specific aspects os Chinese culture.
\end{abstract}

KEYWORDS: sinology; Macao; orientalism.

1 Mestrando em Literatura Portuguesa pela Faculdade de Filosofia, Letras e Ciências Humanas da Universidade de São Paulo (FFLCH/USP). 
É tarefa extremamente difícil buscar uma concepção unívoca que abarque de maneira satisfatória a relação de Camilo Pessanha com Macau. Efetivamente, a sua longa estadia na China pode ser abordada sob o viés do exotismo, como o faz Gustavo Rubim², ou mesmo, como defende Paulo Franchetti ${ }^{3}$, a partir do ponto de partida de uma alegre contingência geradora dos mais diversos efeitos de sentido. Neste caso, a análise necessariamente passará pela compreensão da cultura chinesa sob um olhar intelectualizado do europeu. Uma terceira vertente, da qual prudentemente devemos nos afastar (pela sua identificação a ideias pré-concebidas de simbolismo e pelo apelo fácil ao personalismo), evoca o misticismo que envolve a figura nebulosa do poeta excêntrico, viciado em ópio e dilettanti da sinologia.

Essas três possibilidades respondem a uma exigência de análise da estadia de Camilo Pessanha em Macau como sujeito de cultura, o que necessariamente nos leva ao questionamento sobre a finalidade e os meios a que se submetem seus interesses no estudo dos costumes chineses. Mais ainda: a busca desses parâmetros responde diretamente a determinados referenciais, ou seja, aos ângulos sob os quais ele observa a vida dos chins. Tal mapeamento subjaz e deixa entrever o ponto de vista do crítico Pessanha sobre a dinâmica, o cotidiano, a delícia e a desgraça do cotidiano macaense.

Iniciemos nosso trajeto por um texto do periodista Manuel da Silva Mendes, sinólogo e conhecido de Camilo Pessanha, em que oportunamente compara Hong Kong a Macau. À primeira, colônia inglesa conquistada após a Guerra do Ópio (1842), ele confere um caráter mercantil, no qual o nervoso caminhar de seus habitantes parece expressar o próprio espírito desumanizador do capitalismo. Em favor de uma prosperidade sonhada e duramente trabalhada, parece ter-se perdido o ideal sereno de um bucolismo tardio, traço este que Macau, segundo o autor, mantinha intacto:

Quem põe como principal fim do seu viver ganhar dinheiro, sentirá que vive melhor em Hong Kong do que em Macau; (...) quem prefere viver em tranquilidade, gostará mais da vida de Macau. (MENDES, 1979, p. 26).

Prosperidade e paz, na formulação de Silva Mendes, não coexistem no contexto das colônias ocidentais na China ${ }^{4}$. A distinção é flagrante e reafirma o atraso econômico de Macau (e de Portugal, em última análise) em relação a um território congênere.

2 Professor da Universidade Nova de Lisboa, Gustavo Rubim publicou em 2008 o ensaio Pessanha - Exota, para divulgar a Exposição Weltliteratur: Madrid, Paris, Berlim, São Petersburgo, o Mundo!, ocorrida em Lisboa naquele mesmo ano.

3 "Muito ao contrário de uma decisão emocional, a mudança para a China foi a alternativa possível após anos de esforço para obter um posto de trabalho em Portugal e várias hipóteses e tentativas de emigração" (FRANCHETTI, 2008, p. 10).

${ }^{4}$ A esse respeito, o diplomata João de Andrade Corvo pondera, após constatar um aumento vertiginoso de gastos na administração da cidade entre 1856 e 1873: "Esta exposição rápida dos factos basta para nos convencer de que a emigração contractada por Macau não foi origem de verdadeira prosperidade, nem teve consequencias economicas e sociaes que podessem desculpal-a de seus profundos vícios e iniquidades" (1883, p. 161). Neste período, Macau experimentou um período de grande fluxo emigratório de chineses, o que exigiu um maior repasse à administração pública da cidade, especialmente em relação à vigilância realizada pela polícia. 
Concomitantemente, busca transpor para o domínio do bem-estar espiritual os dons que elevam Macau a um espaço regido por uma economia supramaterial, no melhor estilo ufano e populista. Objetivamente, é muito provável que Silva Mendes remeta a uma superioridade de caráter de seu povo, enaltecendo o gênio português, uma vez que a natureza das colonizações em cada um desses territórios foi pautada por interesses particulares de Portugal e Inglaterra. Pela afirmação do autor, fica implícito que o legado dos portugueses em Macau reside mais num estilo de vida ligado ao despojamento (material e pessoal) do que ao germe capitalista que os ingleses insistiram em plantar em solo oriental. Tal escala de valores, instituída a partir de um juízo algo ressentido, metaforiza involuntariamente a incapacidade portuguesa em modificar uma cultura milenar ligada a preceitos negativos. Cultura essa que Camilo Pessanha minuciosamente descreverá no prefácio do livro Esboço crítico da civilização chinesa, do médico António Filipe de Morais Palha ${ }^{5}$. Evidentemente tais preceitos são determinados pela voz uníssona do colonizador, da qual Camilo Pessanha por vezes se vale, talvez como um interlocutor que pretenda conferir um valor de verdade às coisas que comunica a seus patrícios de Europa e de Macau.

O traço de bucolismo que se destaca na afirmação de Silva Mendes citada acima é absolutamente coincidente com a visão de Pessanha, sendo neste autor transfigurada em concepção de poesia. No ensaio Macau e a gruta de Camões, o poeta visualiza, entre a poesia e sua realização, um movimento de recuo que preenche o espaço entre a elaboração, a memória e a ontologia dos seres que integram os versos. O recuo é por definição o próprio bucolismo: "toda a poesia é, em certo sentido, bucolismo: e bucolismo e regionalismo são tendências do espírito inseparáveis" (PESSANHA, apud FRANCHETTI, 2001, p. 28). Esses referenciais em Camilo Pessanha estão intimamente ligados às percepções estéticas que ele observa em Macau, mas as relações não cessam neste ponto. A China é, para o poeta, um espaço em que vige o imponderável, e talvez por essa razão, uma espécie de liberdade transite sem rédeas por essas sendas. Torna-se, portanto, significativo que o bucolismo esteja ligado à amplidão, à liberdade. Partindo desse ponto, a constatação é a de que a poesia exige um espaço vasto no qual possa atingir com mais viço o seu fulgor. E não é somente em nível formal que se estabelecem essas decorrências, embora a analogia entre o bucolismo como postura de localizar-se na simplicidade remeta fortemente à premência da forma como ser comunicador deste aparente despojamento. Para Paulo Franchetti, este bucolismo está mais ligado à experiência subjetiva que permeia os traços de poesia do que a um suposto idealismo em relação à função revitalizadora da natureza: regionalismo e bucolismo, desta maneira, emergem como vetores da própria identidade do sujeito. Essa

\footnotetext{
5 "A prostituição, o deboche, a pederastia, o sadismo, a preguiça, o parasitismo, a mendicidade, a vagabundagem, o jogo, o lenocínio, a escravatura... A fraude, a chantage, o furto, o roubo, o banditismo, a pirataria, o cativeiro... E de tudo isto todos os dias, - uma exibição permanente de quanto se possa imaginar de mais lastimoso e de mais extravagantemente sinistro, - montão de lixo constituído pelos mais asquerosos detritos, caudal de esgoto arrastando as mais irreconhecíveis escórias humanas.

Ignorância, boçalidade, superstição, deslealdade, covardia, avareza, sensualidade, crueldade, desfaçatez, cinismo, atonia moral... E, coexistindo com estas qualidades morais negativas, a agravar-lhes o efeito imprevisto dos contrastes e pelo disparatado das situações, a inextricável trama de preconceitos, de fórmulas e de convenções (...) dando a todas as relações um acentuado tom de hipocrisia e enredando de dificuldades a vida social, transformada em uma permanente comédia vazia de sentido”. (PESSANHA, 1988, pp. 122-123).
} 
forma de expressão particular adquire um direcionamento ligado à particularidade do momento histórico, ou mesmo da história pessoal, e é por essa razão que há a indissociabilidade entre essas duas forças. A Macau que cerca Camilo Pessanha é a mesma sobre a qual Silva Mendes comentara. A diferença entre eles é que o primeiro entende o bucolismo da cidade como um ente mediador da existência de si e da poesia, ou seja: o apelo à tranquilidade dos sentidos exaspera o intelecto, tornando-o produtivo do ponto de vista da práxis da poesia. No entanto, esse movimento somente acontece quando é algo entranhado, e pode ser reelaborado como pastiche da recordação, simulacro de vida ou poesia; para o segundo, o bucolismo assume um papel revelador em vista do comportamento humano, tendo uma capacidade de distinguir diferentes (e visíveis) tendências em relação a aspectos mais objetivos, como os econômicos e os relativos à saúde. As duas concepções se completam na medida em que subvertem o senso comum que reafirma o bucolismo como situação de estabilidade e sossego.

A citação de Camilo Pessanha ainda refere textualmente a expressão "regionalismo". A princípio enigmático, tal termo não soa tão disparatado se tivermos em mente o contexto em que o poeta enuncia esse preceito. "Exilado" em Macau por vontade própria, e umbilicalmente ligado a Portugal por razões óbvias, Pessanha tece um discurso sobre a China totalmente identificado ao influxo de suas memórias mais caras trazidas de seu país de origem. A personalidade, portanto, é parte constituinte do processo de reavivamento do sentimento regional que a poesia, pela concepção de Pessanha, contém de modo subjacente. De outro modo, não haveria a possibilidade de interpenetração da experiência em domínios afetivos e espaciais diferentes, mas sim a segmentação e ausência de ligação entre o que se viveu no passado e os sentidos que o mantém na atualidade. Esse movimento da memória que extravasa os limites da territorialidade, entretanto, é regido pela fluidez, e diferentemente das fronteiras fisicamente delimitadas, não deve ser explicitamente determinado: o regionalismo de Pessanha pode ser lido como um modo de comunicar-se (ou comunicar a si) por meio de correspondências, metáforas de "tendências de espírito". Tais vetores se coordenam ou buscam algum tipo de reminiscência comum a lugares e épocas diametralmente opostas, como lemos em mais um excerto de Macau e a gruta de Camões:

Em Macau é fácil à imaginação exaltada pela nostalgia, em alguma nesga de pinhal menos frequentada pela população chinesa, abstrair da visão dos prédios chineses, dos pagodes chineses, das sepulturas chinesas, das misteriosas inscrições chinesas (...) e criar-se, em certas épocas do ano e a certas horas do dia, a ilusão de terra portuguesa. Quem estas linhas escreve teve, por várias vezes (há quantos isso vai!) deambulando pelo Passeio da Solidão, a ilusão, bem vivida apesar de pouco mais duradoura que um relâmpago, de caminhar ao longo de uma certa colina da Beira Alta, muito familiar à sua adolescência. (PESSANHA, 1988, pp. 183-4)

A "deambulação" de Pessanha pela cidade constitui uma chave de compreensão do ato de pensar a si. Trata-se de uma oportunidade em que a reminiscência faz emergir das profundezas da consciência uma melancolia que vem à tona como a mais completa das 
percepções. Porque intensa, posiciona o "eu" poético frente a seus dramas, frente às suas questões mais íntimas e assustadoras. Por essa razão, o encontrar-se possui uma dimensão espacial difícil de alijar daquela que concerne ao inconsciente: o ser se constitui em movimento, e é dentro de um tal espaço (o espaço citadino, neste contexto) que se move procurando insights e pistas que completem o enigma da incompletude que vigora na existência. Esta flânerie pode ser, ainda, a busca pela compreensão de si como particularidade frente aos espasmos da cidade em sua brutal acolhida. O limite se afigura como o ponto fulcral da descoberta. O regionalismo, entendido na concepção de Pessanha como uma (re)visitação desses limites, restitui a experiência da integridade pela força da rememoração, ou ao menos a aproxima de uma especulação frutífera, que pode ser a própria poesia ${ }^{6}$.

Nem todos os testemunhos de Camilo Pessanha sobre Macau e especialmente sobre a China, entretanto, são pautados em termos abstratos. Há descrições objetivas de situações que prezam pela sua crueza e veemência, ou mesmo pela ironia fina típica dos grandes escritores. Como exemplo, transcrevemos um trecho de uma visita do poeta a Guangdong, província chinesa próxima a Macau:

E ao balouço fatigante e monótono da cadeirinha que nos conduz para a restinga silenciosa de Shameen, ajardinada e sombreada de banians, tenho a ilusão de que a confusa multidão por entre a qual acabo de atravessar é toda ela um enxurro homogêneo de imundície, como esses canais, infectos como esgoto mas navegados de barcos, do vizinho bairro de Ho-Nam - a Veneza cloacina do Extremo Oriente -, correndo entre monturos e o tardoz de pardieiros arruinados e imundos. (idem, p. 143).

Analisando as imagens da citação, podemos entrever o rebaixamento da ideia do Oriente como lugar de equilíbrio. Comparar a "multidão" de passantes a um "enxurro homogêneo de imundície" e criar um nada honroso epíteto à cidade de Ho-Nam, a "Veneza cloacina", são posturas extremamente duras que demonstram a crueza dos becos escuros, das vias sujas da China real, não idealizada. Camilo Pessanha não pretende refrear a expressividade de sua linguagem ao descrever essas vielas e sua gente, reforçando uma insólita postura de amargor frente ao povo e ao ambiente do lugar que amava. Convém salientar que, no torvelinho dessas imagens repulsivas, Portugal não retorna. À terra natal parecem estar reservadas as primícias da saudade e de uma melancolia (a seu modo) benfazeja. A contraposição é brutal: de um lado, o cotidiano de imundície e trivialidade dos chins; de outro, as memórias grandiosas e eloquentes de um Portugal distante e belo que sobrevive mais à custa da recordação do que da presença. As imagens que Pessanha enuncia da China têm a violência como principal característica, de modo que as paisagens

\footnotetext{
${ }^{6}$ É curioso constatar que Manuel da Silva Mendes relata sensações semelhantes às de Pessanha, embora não as extravase para o domínio poético. Em outubro e novembro de 1929, cinco anos depois da publicação do ensaio Macau e a Gruta de Camões, o cronista escreve no Diário de Notícias de Macau: “(...) percorrendo a Praia Grande até ao chunambeiro, subindo daí para a Rua da Penha, descendo até à Bica de Lilau, dobrando para a Rua do Padre António, tomando pela Rua do Inácio Baptista, cortando para a Rua de São José, não era tudo tão português como qualquer bairro do Porto, de Braga ou de Coimbra? O próprio pavimento das ruas não era a característica calçada à portuguesa?” (MENDES, 1979, p. 22).
} 
que ele compila para o prefácio ao trabalho de Morais Palha são quase inteiramente dedicadas a descrever o aterrador cenário de uma terra desolada, cuja hipertrofia se mostra de maneira cabal a cada esquina. A violência é, no prefácio que o poeta escreveu ao livro de Palha, o filtro pelo qual ele apresentará aos seus patrícios a crônica de um espaço desordeiro. O Esboço crítico da civilizạcão chinesa, na medida em que pretende chancelar cientificamente as impressões dos portugueses de Macau a respeito dos povos do Oriente, pode ser tido como um livro de apresentação para os neófitos. Cabe ressaltar que já num primeiro momento - o do prefácio - Camilo Pessanha buscou resgatar imagens absolutamente cruas do cotidiano das cidades chinesas. Valendo-se de uma espécie de realismo documental, ele realça as primeiras impressões como aquelas que determinam o julgamento do estrangeiro europeu ${ }^{7}$. Neste contexto, à primeira vista, as cidades dos chineses se destacam pela sua completa falta de organização urbanística e social.

Pareceu evidente a Camilo Pessanha que as ruas lodosas de Guangdong não refletiam senão o descaso administrativo dos seus governantes, além de um sistema judiciário que de maneira subliminar é exposto como um amontoado de crueldades, o que ironicamente confere um sentido bastante intenso à conhecida expressão "tortura chinesa". A partir de relatos como o de Pessanha é que o imaginário ocidental pôde criar, recriar e ampliar as suas fantasias $^{8}$, uma vez que os juízos que ele enuncia são em geral um eco de algumas concepções correntes à época nos meios intelectuais. As noções positivistas de "progresso" constam no arcabouço de diagnósticos que conferem à vida chinesa um andamento truncado em razão de certos costumes tidos como prejudiciais, de tal modo generalizado que

desse antagonismo [resultante da hipocrisia da vida social dos chineses] resultam a vaidade pomposa e balofa, (...) um complexo e rigoroso

\footnotetext{
7 Mais uma vez, a remissão a Silva Mendes é recorrente: "Confesso: causaram-me desagradabilíssima impressão os chineses. Eu fazia-os muito outros. Nunca tinha visto nenhum em carne e osso. Conhecia-os porém: conhecia-os das figuras de caixas de fósforos e do Café Chinês da Póvoa de Varzim.” (idem, p. 22). O pasmo do europeu é evidente em vista da realidade citadina da China, no caso, de Hong Kong. Ele descreve a beleza da cidade, contrapondo-a aos modos de seus habitantes: "A cidade, sim, era para ver-se: casarões enormes, estabelecimentos ricos com tão bonitas coisas que até dava vontade de roubá-las e, à noite, iluminação tão profusa, que parecia tudo aquilo um céu aberto.” (ibidem, p. 22).

Ainda neste sentido, o escritor e diplomata Eça de Queirós reconstitui a imagem que os ocidentais mantinham (ou mantêm) dos chineses: "Para o europeu, o chinês é ainda um ratão amarelo, de olhos oblíquos, de comprido rabicho, com unhas de três polegadas, muito antiquado, muito pueril, cheio de manias caturras, exalando um aroma de sândalo e de ópio, que come vertiginosamente montanhas de arroz com dois pauzinhos e passa a vida por entre lanternas de papel, fazendo vénias. [...] Que por trás do rabicho e dos guarda-sóis de papel, e das caturrices, e de todo o exotismo, existam sólidas instituições sociais e domésticas, uma velha e copiosa literatura, uma intensa vida moral, fecundos métodos de trabalho, energias ignoradas, o europeu mediano não o suspeita" (QUEIRÓS, 1997, p. 33-34).

8 Palavra evocada por Homi Bhabha para definir o fenômeno da estereotipia: "O fechamento e coerência atribuídos ao polo inconsciente do discurso colonial e à noção não problematizada do sujeito restringem a eficácia do poder como do saber. [...] É precisamente esta função do estereótipo como fobia e fetiche que, segundo Fanon, ameaça o fechamento do esquema racial/epidérmico para o sujeito colonial e abre a estrada real à fantasia colonial". (BHABHA, 1998, p. 114). Neste mesmo contexto, Edward Said enuncia que "na linguagem de Balfour e Cromer [orientalistas ingleses do século XIX], o oriental é descrito como algo que se julga (como num tribunal), algo que se estuda e se descreve (como num currículo), algo que se disciplina (como numa escola ou prisão), algo que se ilustra (como num manual de zoologia). O ponto é que em cada um desses casos o oriental é contido e representado por estruturas dominadoras". (SAID, 2008, pp. 73-4).
} 
formalismo nos atos jurídicos em que, todavia, predomina a má-fé, um cerimonial de intermináveis cortesias no trato quotidiano, aborrecido e rastejantemente servil, feito de solicitudes fingidas e hiperbólicas adulações. (ibidem, p. 123).

O mundo oficial chinês, ao qual Pessanha procura conferir uma crônica falta de dignidade, é concebido como uma série de vaidades que denunciam a ingerência do estrato pessoal na esfera da prestação de serviços públicos e mesmo do aparato judiciário chinês. Ora, o costume de misturar essas duas dimensões é muito comum em Portugal, onde os limites entre vida pública e privada são muito difíceis de determinar, como o atestam alguns romances de Eça de Queirós ${ }^{9}$ e Camilo Castelo Branco, nos quais a política do sentimento frequentemente invade a noção de espaço político. O próprio Pessanha havia sido vítima deste tipo de trama quando de sua exoneração como magistrado em Mirandela, num episódio em que, da intensa briga entre regeneradores e progressistas, lhe sobrou a inimizade de muitos e, de modo indireto, o final de sua carreira jurídica como bacharel (àquela altura subdelegado ${ }^{10}$ ). Portanto, qualquer parecer em relação a esses comportamentos observados nos rituais administrativos chineses pode não ser apenas coincidência, mas sim uma projeção de uma percepção universal relativa à degenerescência do poder. Os chineses, por esta via, não devem em nada aos europeus em relação à boa vontade que ostentam no tocante à arte oficial de enganar e de adular. A corrupção, desse modo, levada quase ao ponto do escárnio por força da indignação subliminar do discurso de Pessanha é um ponto muito significativo na análise que o poeta empreende das relações escusas que permeiam as cidades.

Os fortes contornos com os quais Camilo Pessanha descreve a violência presente nas ruas da China são outra dimensão, mais palpável, da venalidade da justiça e sua apresentação como espetáculo deplorável. A prática do leng-chi, à qual o poeta dedica um bom número de páginas em seu prefácio a Morais Palha, surpreende-o pela crueldade, mas o que de fato o exaspera é a absoluta atonia e indiferença do público presente, totalmente acostumado a encontrar diuturnamente num mesmo espaço a sua casa, o seu trabalho e o fatal destino dos condenados:

\footnotetext{
9 Acerca desta ingerência, o exemplo mais cabal é A ilustre casa de Ramires, prontamente identificada como metáfora da vida política portuguesa. Em menor escala, Camilo Castelo Branco também se move por entre essas referências, lidando em obras como $A$ brasileira de Praz̧ins com a temática do engajamento político e sua transformação em questão pessoal.

10 António Dias Miguel assim relata o episódio citado: “O dito administrador do concelho, assanhado regenerador, era acusado de conivente na cena de agressão a um pobre funcionário de filiação progressista, que dele dependia, agressão levada a cabo por um bando de desordeiros da vila, todos eles filiados no outro partido. Chegado o dia da audiência, 15 de outubro, o subdelegado [Pessanha], como lhe competia (...) analisa os problemas em causa, sem curar dos interesses inconfessáveis que se escondiam por detrás do julgamento, indiferente às cabalas e às protecções partidárias. (...) A escandalosa protecção do juiz, o apoio dos jurados suspeitos, um dos quais fora subdelegado substituto pouco antes, e ainda a coacção da subserviência do pobre funcionário, levaram o administrador do concelho à absolvição. (...) O administrador do concelho queixa-se à Procuradoria do Reino, certo da sua injusta vitória, justificada por falsas aparências. Logra até impedir que o poeta se apresente ao concurso para delegado." (apud PIRES, 1990, p. 108).
} 
De vez em quando, ranchos de mulheres atravessam o pretório, carregadas de baldes de água, conversando umas com as outras, de todo alheias ao espetáculo, para elas quotidiano (...). As execuções, por decapitação ou pelo leng-chi (a morte lenta por sucessivas mutilações operadas à faca), realizam-se, como dito ficou, em um miserável beco suburbano (...). Mas um dos mais prodigiosos segredos da habilidade chinesa é a da utilização dos espaços reduzidos: veja-se por exemplo, aqui em Macau, que numerosa população de famílias se acomoda por vezes, em qualquer minúsculo tugúrio. No execution ground não só se vive à larga a volumosa indústria de produtos cerâmicos, mas também ali o carrasco exercita o seu mister desafogadamente, e em proporções respeitáveis, dizimando na legião de malfeitores que infesta o KuongTung. (PESSANHA, 1988, p. 135).

A naturalização da morte e as péssimas condições de vida dos chineses são figuradas com um quê de ironia por Pessanha: o carrasco que com tranquilidade cumpre o seu trabalho, o "gosto" dos macaenses por se espremerem em espaços minúsculos... O olhar do cronista dificilmente o abandona, a não ser por força da elaboração poética, e dessa tensão é que vêm as ondas de fascínio e repulsa à vastíssima cultura que o cerca.

Tais juízos amargos e espirituosamente encadeados podem demonstrar duas coisas: em primeiro lugar, podem pretender demonstrar o primado da racionalidade jurídicocientífica da Europa ante as nações "não-civilizadas" do Oriente. O propósito colonialista não fazia parte do repertório das principais preocupações de Camilo Pessanha se comparado, por exemplo, aos discursos do jornalista Oliveira Martins, e por isso mesmo há uma certa dificuldade em aceitar pacificamente esta possibilidade. A outra hipótese, mais plausível, confere à linguagem um papel central na própria descoberta do poeta como sujeito enunciador de uma espécie pioneira de orientalismo. Este conjunto de saberes, se analisado pela sua seriedade científica, seria prontamente posto em dúvida. Se tais análises, porém, forem observadas sob um olhar ligado à autoria e personalidade, afiguram-se atentas às modalizações de um intelecto igualmente aberto ao abjeto e ao sublime. Camilo Pessanha incorpora à sua escrita das cidades orientais um repertório altamente valioso de imagens que transcendem a banalidade que aparentemente sustentam. As paisagens que ele observa transigem quase naturalmente para o plano da linguagem, se as entendermos como uma manifestação quase teatral das esquetes da vida chinesa. O gracejo, a ênfase, a seriedade e mesmo a pretensão de seriedade são componentes desse complexo e fascinante universo chamado China, que Camilo Pessanha buscou transmitir sem retoques e nem idealizações, ou seja, o mais fidedignamente possível. 


\section{BIBLIOGRAFIA}

BHABHA, Homi. O local da cultura. Trad. de Myriam Ávila, Eliana Lourenço de Lima Reis e Gláucia Renate Gonçalves. Belo Horizonte: UFMG, 1998.

CORVO, João de Andrade. Estudos sobre as provincias ultramarinas. Lisboa: Typographia da Academia Real das Sciencias de Lisboa, 1883.

FRANCHETTI, Paulo. Nostalgia, exílio, melancolia: leituras de Camilo Pessanha. São Paulo: EdUSP, 2001.

. O essencial sobre Camilo Pessanha. Lisboa: Imprensa Nacional - Casa da Moeda, 2008.

MENDES, Manuel da Silva. Macau: Impressões e recordações. Lisboa: Quinzena de Macau, 1979.

MIGUEL, António Dias. Camilo Pessanha e a magistratura. In: PIRES, Daniel. (Org.). Homenagem a Camilo Pessanha. Macau: Instituto Português do Oriente / Instituto Cultural de Macau, 1990.

PESSANHA, Camilo. Contos, crónicas, cartas escolbidas. Org. António Quadros. Lisboa: Europa-América, 1988.

Clepsydra. Ed. crítica de Paulo Franchetti. Lisboa: Relógio d’Água, 1995.

QUEIRÓS, Eça de. Chineses e japoneses. Lisboa: Cotovia/Fundação Oriente, 1997.

RAMOS, Manuela Delgado Leão. António Feijó e Camilo Pessanba no panorama do orientalismo português. Lisboa: Fundação Oriente, 2001.

RUBIM, Gustavo. Pessanha - Exota. : Lisboa: Catálogo da Exposição Weltliteratur: Madrid, Paris, Berlim, São Petersburgo, o Mundo!: Calouste Gulbenkian, 2008.

SAID, Edward. Orientalismo. Traduzido por Rosana Eichenberg. São Paulo: Companhia das Letras, 2008.

SIMAS, Mônica. Margens do destino: Macau e a literatura em língua portuguesa. São Caetano do Sul: Yendis, 2007. 